\title{
CERTIFICAÇÃO E MARCA NAS TRANSAÇÕES ENTRE VAREJISTAS E DISTRIBUIDORES DE CARNES ESPECIAIS
}

Certification and brand in transactions between retailers and distributors of specialty meat

Lechan Colares-Santos

Amanda Ferreira Guimarães

Sandra Mara de Alencar Schiavi

Iolanda Ivantes

José Paulo de Souza 


\title{
CERTIFICAÇÃO E MARCA NAS TRANSAÇÕES ENTRE VAREJISTAS E DISTRIBUIDORES DE CARNES ESPECIAIS
}

\author{
Certification and brand in transactions between retailers and distributors of \\ specialty meat
}

\author{
Lechan Colares-Santos \\ Amanda Ferreira Guimarães \\ Sandra Mara de Alencar Schiavi \\ Iolanda Ivantes \\ José Paulo de Souza
}

\begin{abstract}
Resumo: O objetivo foi analisar como a certificação e a marca influenciam as transações entre distribuidores e varejistas de carnes especiais nas cidades de Presidente Prudente/SP e Maringá/PR. A pesquisa, qualitativa e descritiva, fundamentou-se na Economia dos Custos de Mensuração e abrangeu entrevistas semiestruturadas com 10 varejistas de carnes especiais em Presidente Prudente/SP e Maringá/PR. Como resultados, observou-se que a raça é o principal aspecto de diferenciação do produto, originando dimensões de difícil mensuração, em sua maior parte mensuradas subjetivamente, tais como textura, marmoreio e sabor. Nem todos os atributos de qualidade são remunerados, implicando espaço para apropriação de valor. Conclui-se que a certificação e a reputação possibilitaram estruturas de governança menos complexas, reduzindo custos de mensuração, já as marcas não foram relevantes.
\end{abstract}

Palavras-chave: Pecuária de corte, Diferenciação, Agronegócio.

\begin{abstract}
The objective was to analyze how the certification and the brand influence the transactions between distributors and retailers of specialty meat in Presidente Prudente/SP and Maringá/PR. The qualitative and descriptive research was based on the Economics of Measurement Costs and included semistructured interviews with 10 specialty meat retailers in Presidente Prudente/SP and Maringá/PR. As a result, breed is the main aspect of product differentiation, giving rise to dimensions that are difficult to measure, mostly subjectively measured, such as texture, marbling and flavor. Not all quality attributes are remunerated, implying space for value appropriation. It was concluded that certification and reputation made possible less complex governance structures, reducing measurement costs, and the brands were not relevant.
\end{abstract}

Keywords: Beef cattle, Differentiation, Agribusiness.

Resumen: El objetivo fue analizar cómo la certificación y la marca influyen en las transacciones entre distribuidores y minoristas de carnes especiales en las ciudades de Presidente Prudente/SP y Maringá/PR. La investigación, cualitativa y descriptiva, se fundamentó en la Economía de los Costos de Medición e incluyó entrevistas semiestructuradas con 10 minoristas de carnes especiales en Presidente Prudente/SP y Maringá/PR. Como resultados, se observó que la raza es el aspecto principal de la diferenciación del producto, originando dimensiones de difícil medición, en su mayor parte medidas subjetivamente, como la textura, el marmoleo y el sabor. Ni todos los atributos de calidad son remunerados, lo que implica espacio para la apropiación de valor. Se concluyó que la certificación y la reputación hicieron posibles estructuras de gobernanza menos complejas, reduciendo los costos de medición, mientras que las marcas no fueron relevantes.

Palavra clave: Ganado vacuno, Diferenciación, Agronegocios 
IGepec, Toledo, V. 24, n.1, p. 9-26, jan./jun. 2020. 


\section{INTRODUÇÃO}

O agronegócio tem significativa importância para o Brasil, o posicionando como referência internacionalmente. No ano de 2017, o Produto Interno Bruto Brasileiro (PIB) do agronegócio correspondeu a 21,6\% do total do PIB brasileiro, sendo que a pecuária foi responsável por 29,73\% daquele valor (CEPEA, 2018). Além disso, no ano de 2018, o Brasil foi o maior exportador de carne bovina (toneladas) e obteve a segunda maior produção mundial (toneladas) (USDA, 2019).

Contudo, apesar dos números favoráveis e do bom desempenho da pecuária brasileira, estudos evidenciam problemas de competitividade nesse Sistema Agroindustrial (SAG), especialmente no que se refere a falhas de coordenação (CALEMAN; SPROESSER; ZYLBERSZTAJN, 2008). As relações entre os agentes são majoritariamente caracterizadas pela presença de oportunismo e elevada assimetria de informação, nas quais o foco tem sido o lucro a curto prazo (BUAINAIN; BATALHA, 2007).

De forma alternativa, tem emergido subsistemas voltados para a diferenciação dos produtos, tais como os Sistemas Agroalimentares Diferenciados (SADs), que estão relacionados, de alguma forma, à descommoditização do produto (BÁNKUTI, 2016). Tais subsistemas envolvem diferenciação, compreendendo dimensões que podem não ser facilmente mensuráveis, tais como. como maciez, cor, sabor e atributos de crença (MACEDO; MORAES, 2009).

Sob a perspectiva da Economia dos Custos de Mensuração (ECM), a continuidade desses subsistemas depende de estruturas de governança que garantam direitos de propriedade ao longo de toda a cadeia, o que pode envolver maiores custos de mensuração (BARZEL, 2005). De forma alternativa, o desenvolvimento de marcas e certificações de terceira pode viabilizar a adoção de estruturas de governança menos complexas, resultando em menores custos de transação (DEATON, 2004; BARZEL, 2005; CALEMAN; SPROESSER; ZYLBERSZTAJN, 2008).

A certificação por uma terceira parte com elevada reputação pode reduzir a assimetria de informação entre os agentes (DEATON, 2004; BARZEL, 2005). A marca, por sua vez, pode atenuar incertezas quanto à presença dos atributos de qualidade, aumentando a propensão dos consumidores a remunerar de acordo com a qualidade do produto (FERNÁNDEZ-BARCALA; GONZÁLEZ-DÍAZ, 2006; MORALES et al., 2013). Uma vez que a perpetuidade de subsistemas diferenciados do retorno adequado aos investimentos, a certificação e marca são mecanismos que podem viabilizar a continuidade desses sistemas.

Ao se considerar as dificuldades de mensuração e as relações à jusante da cadeia, falhas nas transações podem comprometer a remuneração e a distribuição do valor gerado (BÁNKUTI, 2016), gerando desestímulos à agregação de valor no longo prazo. Dadas falhas de coordenação em SADs da carne bovina, e as dificuldades de mensuração dos atributos associadas ao ativo, este trabalho tem como objetivo analisar como a certificação e a marca influenciam as transações entre distribuidores e varejistas de carnes especiais nas cidades de Presidente Prudente/SP e Maringá/PR.

O trabalho está organizado em cinco seções. Além desta introdutória, a segunda seção apresenta as fundamentações teóricas que sustentaram o estudo. A terceira descreve os procedimentos metodológicos adotados. $\mathrm{Na}$ quarta seção, são apresentados e discutidos os resultados da pesquisa. A última seção versa sobre as conclusões desta pesquisa. 


\section{REVISÃO DE LITERATURA}

\subsection{ECONOMIA DOS CUSTOS DE MENSURAÇÃO}

A ECM surgiu com intuito de fornecer uma alternativa à escolha da organização das firmas. Barzel (2005), seu precursor, argumenta que a realização das trocas requer informações tanto sobre o que vai ser trocado, em suas dimensões, quanto sobre as condições no qual as trocas irão ocorrer. Diferente do mundo Walrasiano, em que a informação é perfeita e não há custos para transacionar, o modelo de Barzel assume que a informação é cara de ser produzida e complexa de ser transmitida (BARZEL, 2005).

Barzel (2005) argumenta que um ativo é composto por diversos atributos, e que é a informação sobre tais atributos, a responsável por conferir propriedade sobre eles. É a tomada de conhecimento da composição das mercadorias trocadas que permite a definição dos proprietários dos atributos que compõem o ativo. Para o autor existem dois tipos de direitos de propriedade: direito econômico e direito legal. $\mathrm{O}$ primeiro refere-se à habilidade de usufruir de determinada mercadoria direta ou indiretamente, e o segundo, é a propriedade atribuída a determinado agente por meio de mecanismo legal (Estado) (BARZEL, 1997, 2005).

Segundo Zylbersztajn (2005b), o direito legal impacta no direito econômico na medida em que, se o Estado não é capaz de oferecer soluções a um menor custo, as partes optam por adotar mecanismos privados para protegerem seus direitos econômicos. Isso acontece, em grande parte, nos casos em que a mensuração das dimensões transacionadas é difícil, e, portanto, não há informações disponíveis para que o Estado garanta (BARZEL, 2005). Essa atribuição de propriedade está fundada na lógica de maximização de valor, logo, de proteção de valor. Essa maximização de valor se torna real na medida em que há a concessão de propriedade àquele que é reclamante residual do ativo, e, portanto, apto a proteger contra a dissipação de valor (ZYLBERSZTAJN, 2005b).

Entretanto, Barzel (1997) afirma que a informação é incompleta, e por isso os direitos de propriedade não são bem definidos. Assim, os agentes dispenderão esforços para capturar o valor que está em domínio público (BARZEL, 1997, 2005). O racional da teoria, portanto, é baseado na eficiência em adotar estruturas de governança que tenham maior capacidade de maximização de valor da transação por meio da proteção dos direitos de propriedade sobre as dimensões envolvidas na transação (ZYLBERSZTAJN, 2005b).

A depender da mensurabilidade dos atributos, Barzel (2005) propõe quatro formas de organização das atividades: relações de risco e leilões, relações contratuais, relações de longo prazo e a organização interna à firma (integração vertical), em que cada uma delas difere no tocante às informações requeridas. As relações de risco e os leilões são, segundo Barzel (2005), as formas mais simples de transacionar. Nesse tipo de troca, a informação é coletada ex ante. Contudo, esta relação é exposta à duplicação de mensuração, pois, tanto vendedores quanto compradores a fazem, tornando-a, portanto, mais dispendiosa (BARZEL, 2005).

O segundo tipo de organização ao qual Barzel (2005) se refere são as relações contratuais. Esse tipo de relação acontece com apoio do mecanismo legal (Estado), que atua como alicerce para a condução das transações. Nesse caso, os atributos passíveis de serem contratados são aqueles que podem ser verificáveis e mensuráveis. Contudo, diferente das relações de risco, nesse tipo de troca os atributos contratáveis podem ser aqueles em que a medição acontece somente durante o consumo (BARZEL, 2005). Atributos difíceis de serem verificáveis, e, portanto, sujeitos a mensurações subjetivas 
(como sabor e aparência), são indicados de serem transacionados via relações de longo prazo, ou até mesmo pela integração vertical (BARZEL, 2005).

Relações de longo prazo implicam promessas quanto à conformidade das dimensões. Tais promessas possibilitam aos compradores não fazerem a mensuração no momento da troca e, então, realizarem somente no momento do consumo (BARZEL, 2005). Isso é especialmente importante para atributos difíceis, e custosos de serem mensurados. Apesar disso a mensuração durante o consumo é subjetiva e abre margem para a ocorrência de perdas (BARZEL, 2005).

Por fim, da mesma forma que as relações de longo prazo, a integração vertical é adequada quando a mensuração é difícil de ser realizada, ou envolve elevados custos (BARZEL, 2005). Entretanto, enquanto as relações de longo prazo são viabilizadas pela presença de reputação entre as partes, a integração vertical é relevante nos casos em que há a existência de atributos difíceis de serem mensuráveis, mas, sem a construção de reputação entre os agentes (CALEMAN et al., 2006). A integração vertical, para Barzel (2005), ainda facilita a transmissão de informação reduzindo custos para garantir direitos econômicos e de proteção contra apropriação de valor pela transferência de baixa performance entre os agentes.

De modo geral, Barzel (2005) argumenta que a possibilidade de mensuração define a forma contratual. Dimensões fáceis de serem mensuradas podem ser contratadas, sendo, em caso de disputas, protegidas pelo Estado. Dimensões difíceis de serem mensuradas são propensas a serem transacionadas via relações de longo prazo amparadas por salvaguardas baseadas na reputação dos agentes e regras formais ou pela integração vertical (BARZEL, 2005).

\subsection{CUSTOS DE MENSURAÇÃO, CERTIFICAÇÃO E MARCA}

Certificação envolve um conjunto de atividades realizadas por um órgão independente da relação comercial, ou seja, uma terceira parte, que tem por objetivo atestar publicamente que determinado bem, processo ou serviço atende as normas técnicas, ou está em conformidade com requisitos específicos de qualidade (SANTOS et al., 2017). No que tange à ECM, a certificação permite que as dimensões sejam delimitadas, e, portanto, viabiliza que direitos de propriedade sejam definidos de forma mais eficiente. Isso faz com que a dissipação de valor seja reduzida, e a assimetria de informação minimizada.

Diante da revelação das informações por uma terceira parte de elevada reputação, os custos de monitorar, e, portanto, de mensurar tais dimensões pela firma podem ser reduzidos (DEATON, 2004; BARZEL, 2005; CALEMAN; SPROESSER; ZYLBERSZTAJN, 2008). Uma vez que os custos pela mensuração são transferidos à uma terceira parte, a firma pode reduzir custos de mensuração. Logo, a transação pode ser realizada via relações de longo prazo ou pelo mecanismo de mercado conforme proposto por Barzel (2005).

Ademais, compradores podem estar dispostos a remunerar de forma diferenciada em função do acesso à informação daquilo que estão recebendo (BARZEL, 1985). Logo, a certificação se apresenta como um mecanismo que pode possibilitar o retorno pelos investimentos empreendidos em busca de qualidade. Nesse contexto, estudos mostram que a certificação por qualidade e informações de rastreabilidade se mostraram significativas na disposição dos consumidores em remunerar de forma diferenciada pela carne de porco (KEHAGIA; LINARDAKIS; CHRYSSOCHOIDIS, 2007; BARCELLOS et al., 2012; WU et al., 2015). Uma vez que a certificação amplia a disposição do consumidor em remunerar a mais pelo produto (MORALES et al., 2013), observa-se, em consenso com Trienekens (2011), que os mecanismos de certificação 
podem ser vistos como mecanismos úteis para a sobrevivência de sistemas voltados para qualidade.

Outro fator de significativa importância no processo de troca é a marca. A marca se constitui como um mecanismo que reduz a incerteza em relação a presença dos atributos de qualidade associados ao produto (FERNÁNDEZ-BARCALA; GONZÁLEZDÍAZ, 2006). Assim como a certificação, ao mesmo tempo em que a marca pode garantir a presença dos atributos de qualidade, ela aumenta a propensão do consumidor a remunerar a mais pela qualidade (WACHENHEIM; ALONSO; DUMLER, 2000; FERNÁNDEZ-BARCALA; GONZÁLEZ-DÍAZ, 2006; MORALES et al., 2013).

Em suma, a certificação e a marca permitem o movimento do continuum de uma estrutura de governança à outra com base na sua garantia de informações. Atributos transacionáveis via integração vertical, por meio da garantia de informações que a certificação oferece, podem ser transacionados via relações de longo prazo ou relações de mercado (BARZEL, 2005; CALEMAN; SPROESSER; ZYLBERSZTAJN, 2008). Mesmo diante de elevada especificidade de ativos, a mensuração, por meio da certificação e marca, garante transações por meio de mecanismos alternativos à integração vertical. Isso reduz custos tanto de mensuração quanto de transação, pois, possibilitam maior garantia dos direitos de propriedade e, ao mesmo tempo, reduz custos de gerenciamento (BARZEL, 2005).

\section{METODOLOGIA}

O presente trabalho caracteriza-se como uma pesquisa qualitativa (MERRIAM, 1998), do tipo descritiva (TRIVIÑOS, 1987). Em uma etapa preliminar, foi feito um levantamento de dados secundários estatísticos e acadêmicos para a compreensão de SAGs, SADs e do SAG da carne bovina no Paraná e São Paulo. As bases para dados estatísticos foram: o Instituto Brasileiro de Geografia e Estatística (IBGE), o Departamento de Agricultura dos Estados Unidos (USDA), o Ministério da Agricultura, Pecuária e Abastecimento (MAPA), e o Anuário da Pecuária Brasileira (ANUALPEC). As bases acadêmicas foram trabalhos sobre a cadeia produtiva de carne bovina em sistemas convencionais, sistemas diferenciados (de certificação, qualidade, e outros distintos do convencional), e de formas organizacionais alternativas (verticais e horizontais), publicados em periódicos nacionais e internacionais, livros e capítulos de livros, teses e dissertações, artigos de anais de eventos científicos e relatórios de pesquisa.

Em etapa posterior, realizou-se o levantamento de dados primários por meio de entrevistas semiestruturadas com representantes do varejo de carnes especiais em Presidente Prudente/SP e Maringá/PR. A escolha pelas cidades se deu pelas iniciativas para produção de carnes consideradas especiais nesses estados (EMATER, 2019), pela concentração de frigoríficos com registro no Sistema de Inspeção Federal (SIF) (ABIEC, 2019) e sobretudo pelo ambiente institucional distinto observados em ambas cidades, que poderiam contribuir com características e formação de arranjos institucionais heterogêneos.

Já a escolha dos entrevistados se deu por critério de acessibilidade, juntamente com o método de bola de neve. Buscou-se abarcar diferentes formatos de varejo, incluindo na pesquisa açougues e restaurantes, sendo configurados em diferentes tamanhos e tempo na atividade.

Tendo como critério a convergência e saturação dos dados, foram realizadas um total de 10 entrevistas com representantes de empresas varejistas do segmento de carnes especiais, sendo quatro na cidade de Presidente Prudente/SP (P1, P2, P3, P4) e 
seis na cidade de Maringá/PR (M1, M2, M3, M4, M5, M6). As entrevistas foram realizadas entre maio e junho de 2016, sendo gravadas e transcritas na íntegra, para posterior análise. As características dessas empresas são apresentadas na seção de caracterização.

Em seguida, foi realizada a leitura dos artigos e a análise dos dados foi realizada por meio da técnica de análise de conteúdo (BARDIN, 1979). Essa etapa seguiu as fases de pré-análise, exploração do material, e tratamento dos resultados. As categorias foram definidas a partir do material teórico, e foram: dimensões envolvidas na transação, certificação, marca e estrutura de governança. O Quadro 1 representa o quadro de análise que guiou o estudo.

Quadro 1: Quadro de análise

\begin{tabular}{|c|c|c|c|}
\hline $\begin{array}{l}\text { Categoria } \\
\text { de análise }\end{array}$ & $\begin{array}{c}\text { Questão de } \\
\text { pesquisa }\end{array}$ & Definição teórica & $\begin{array}{c}\text { Variáveis } \\
\text { operacionais }\end{array}$ \\
\hline $\begin{array}{l}\text { Dimensões } \\
\text { envolvidas } \\
\text { na } \\
\text { transação }\end{array}$ & $\begin{array}{l}\text { Quais e como são } \\
\text { mensuradas as } \\
\text { dimensões do ativo? }\end{array}$ & $\begin{array}{l}\text { Dimensões que compõem um } \\
\text { ativo, nas quais devem ter seus } \\
\text { direitos de propriedade } \\
\text { distribuídos. Essa distribuição } \\
\text { depende da possibilidade de } \\
\text { mensuração dessas dimensões, } \\
\text { que varia em termos de } \\
\text { dificuldade (BARZEL, 2005) }\end{array}$ & $\begin{array}{l}\text { Na pecuária de corte sã } \\
\text { exemplos: peso, } \\
\text { tamanho, precocidade, } \\
\text { acabamento de } \\
\text { gordura, marmoreio, } \\
\text { cor da carne/gordura, } \\
\text { sabor e maciez }\end{array}$ \\
\hline Certificação & $\begin{array}{c}\text { Como são } \\
\text { configuradas as } \\
\text { certificações nas } \\
\text { transações de carne } \\
\text { bovina? }\end{array}$ & $\begin{array}{l}\text { Processo no qual uma entidade } \\
\text { independente ( } 3^{\mathrm{a}} \text { parte) afere se } \\
\text { determinado produto atende às } \\
\text { normas técnicas (ABNT, 2019). }\end{array}$ & $\begin{array}{l}\text { Selos e certificados que } \\
\text { atestem atendimento } \\
\text { aos atributos } \\
\text { transacionados }\end{array}$ \\
\hline Marca & $\begin{array}{c}\text { Como são } \\
\text { configuradas as } \\
\text { marcas nas transações } \\
\text { entre distribuidores e } \\
\text { varejistas de carnes } \\
\text { especiais? }\end{array}$ & $\begin{array}{l}\text { Representação simbólica de uma } \\
\text { entidade que carrega significado e } \\
\text { associações (KOTLER, 2003) }\end{array}$ & $\begin{array}{l}\text { Símbolo que permite } \\
\text { associar o produto a } \\
\text { empresa ofertante }\end{array}$ \\
\hline $\begin{array}{l}\text { Estrutura } \\
\text { de } \\
\text { governança }\end{array}$ & $\begin{array}{l}\text { Como são } \\
\text { configuradas as } \\
\text { estruturas de } \\
\text { governança nas } \\
\text { transações entre } \\
\text { distribuidores e } \\
\text { varejistas de carnes } \\
\text { especiais? }\end{array}$ & $\begin{array}{l}\text { Modo pelo qual as transações são } \\
\text { executadas (WILLIAMSON, 1985; } \\
\text { BARZEL, 2005) }\end{array}$ & $\begin{array}{l}\text { Relações de risco, } \\
\text { leilões, contratos, } \\
\text { relações de longo } \\
\text { prazo, internalização à } \\
\text { firma }\end{array}$ \\
\hline
\end{tabular}
$\mathrm{ABNT}$

Fonte: Elaborado pelos autores com base em Williamson (1985), Kotler (2003), Barzel (2005) e

Como processo de análise de dados, as entrevistas transcritas foram codificadas a partir das categorias de análise. A fim de transpor e operacionalizar essas categorias, adotou-se variáveis operacionais também oriundas do arcabouço teórico. Como pode ser observado no Quadro 1, investigou-se conteúdos associados às dimensões envolvidas nas transações, mais especificamente peso, tamanho, precocidade, acabamento de gordura, marmoreio, cor da carne/gordura, sabor e maciez; certificações, por meio de selos e certificados que assegurem a presença dos atributos transacionados; marcas, que permitam o consumidor associar o produto a empresa ofertante; por fim, estrutura de governança, como mercado spot, contratos, integração vertical e as derivações de ambas estruturas.

Após a etapa de codificação, relatórios por categoria foram gerados, viabilizando a análise qualitativa de conteúdo, em detrimento à análise de ocorrência de palavras. 
Por fim, os dados foram organizados e analisados possibilitando as inferências e considerações finais. A seção quatro apresenta resultados e discussão.

\section{RESULTADOS E DISCUSSÃO}

Os resultados da pesquisa estão organizados em três partes. Na primeira parte os agentes são caracterizados de acordo com porte e ramo de atuação. Na segunda parte são apresentadas as dimensões envolvidas na transação. Por fim, na terceira parte as transações são caracterizadas de acordo com a estrutura de governança adotada pelos agentes.

\subsection{CARACTERIZAÇÃO DOS CASOS}

Os agentes varejistas se configuram em duas boutiques de carnes, quatro açougues e quatro restaurantes. $O$ tempo na atividade de cada varejo varia entre nove meses e 25 anos. Quanto ao tamanho, tomando como base a definição do SEBRAE (2013), quatro deles são caracterizados como pequenas empresas, enquanto os outros seis como microempresas. O Quadro 2 sintetiza a caracterização das 10 empresas envolvidas na pesquisa.

No que diz respeito aos fornecedores, observou-se, tanto para os varejistas da cidade Presidente/Prudente, quanto da cidade de Maringá/PR, que os principais são: açougues, cooperativas, centros distribuidores e frigoríficos, podendo os varejistas comercializarem com mais de um fornecedor. Os fornecedores estão localizados nos Estados do Mato Grosso do Sul, Paraná, São Paulo e Rio Grande do Sul. A média do tempo de relação com o fornecedor é de cinco anos, sendo o mínimo um mês, e o máximo 17 anos. 
Quadro 2: Caracterização dos agentes varejistas entrevistados

\begin{tabular}{|c|c|c|c|c|c|c|c|}
\hline Varejo & Formato & $\begin{array}{c}\text { Tempo } \\
\text { no } \\
\text { (ancado }\end{array}$ & $\begin{array}{c}\text { Número de } \\
\text { funcionários }\end{array}$ & Fornecedor & $\begin{array}{c}\text { Localização } \\
\text { do } \\
\text { fornecedor }\end{array}$ & $\begin{array}{c}\text { Duração da } \\
\text { ralação com } \\
\text { fornecedor } \\
\text { (mínimo/anos) }\end{array}$ & $\begin{array}{c}\text { Duração da } \\
\text { relação com } \\
\text { fornecedor } \\
\text { (máximo/anos) }\end{array}$ \\
\hline P1 & Boutique & 3 & 3 & $\begin{array}{c}\text { Frigoríficos, } \\
\text { distribuidores }\end{array}$ & São Paulo & 1 & 7 \\
\hline P2 & Boutique & 8 & 3 & $\begin{array}{c}\text { Frigoríficos, } \\
\text { distribuidores }\end{array}$ & São Paulo & 2 & $\begin{array}{c}\text { Não soube } \\
\text { dizer }\end{array}$ \\
\hline P3 & Açougue & 6 & 30 & Frigoríficos & São Paulo & 1 & 6 \\
\hline P4 & Restaurante & 9 meses & 9 & Frigoríficos & São Paulo & 9 meses & 9 meses \\
\hline M1 & Restaurante & 8 & 6 & Açougue & Paraná & 6 & 6 \\
\hline M2 & Restaurante & 6 & 12 & Frigoríficos & $\begin{array}{c}\text { Mato } \\
\text { Grosso do } \\
\text { Sul e São } \\
\text { Paulo }\end{array}$ & 1,5 & 4 \\
\hline M3 & Restaurante & 25 & 40 & $\begin{array}{c}\text { Frigoríficos e } \\
\text { distribuidores }\end{array}$ & $\begin{array}{c}\text { Rio Grande } \\
\text { do Sul e } \\
\text { São Paulo }\end{array}$ & 1 mês & 6 \\
\hline M4 & Açougue & 7 & 3 & Frigoríficos & Paraná & 6 & 17 \\
\hline M5 & Açougue & 23 & 9 & $\begin{array}{c}\text { Frigoríficos, } \\
\text { distribuidores, } \\
\text { cooperativa }\end{array}$ & $\begin{array}{c}\text { Paraná, } \\
\text { Rio Grande } \\
\text { do Sul e } \\
\text { São Paulo }\end{array}$ & 1 mês & \\
\hline & Açougue & 5 & 5 & $\begin{array}{c}\text { Frigoríficos e } \\
\text { cooperativa }\end{array}$ & $\begin{array}{c}\text { Paraná, } \\
\text { Rio Grande } \\
\text { do Sul e } \\
\text { São Paulo }\end{array}$ & 1 mês & 4 \\
\hline
\end{tabular}

Fonte: Elaborado pelos autores com base nos dados primários.

Os principais aspectos de diferenciação são, além da precocidade, as raças dos animais, tais como Angus, Bonsmara e Wagyu, que, por sua vez, conferem atributos de qualidade como sabor, maciez, e acabamento de gordura. $\mathrm{O}$ público consumidor desses varejistas é classificado como classe média, classe média alta e classe alta. Contudo, identificou-se que nem todos os atributos de qualidade são reconhecidos e, portanto, remunerados pelos consumidores. Segundo os entrevistados, os consumidores não remuneram a mais pelo produto oriundo de um animal precoce de raças como o Nelore. Contudo, remuneram, em média, 35\% acima do preço do produto tradicional por um produto originado de um animal das raças Angus e Bonsmara, e cerca de $300 \%$ pela raça Wagyu.

\subsection{DIMENSÕES ENVOLVIDAS NA TRANSAÇÃO}

No que tange às dimensões importantes para a transação, verificou-se que elas são consideradas em três momentos: no momento da realização da troca; após a troca e, portanto, durante o preparo; e nem mesmo após a troca. Dimensões observadas no momento da troca são: raça e precocidade, sanidade, embalagem, tamanho e peso, temperatura e coloração, e são mensuradas por todos os agentes varejistas entrevistados. Após a troca são analisadas: textura, cheiro, marmoreio e maciez, sendo mensuradas somente pelos varejistas caracterizados como restaurantes. E, por fim, o sabor não é mensurado nem mesmo após a troca.

- Raça e precocidade: os atributos raça e precocidade são verificados pelo varejista a partir dos selos que acompanham o produto. Uma vez que são certificados por uma terceira parte de elevada reputação, os entrevistados afirmam que existe uma 
confiança quanto a essas informações. As informações são sinalizadas em todas as embalagens dos cortes, de forma visual. Cabe destacar que essa certificação, além de trazer informações sobre a raça e a precocidade do animal, disponibiliza informações aos varejistas quanto à rastreabilidade do boi, a data de abate e prazo de validade.

- Sanidade: assim como a raça e a precocidade, a mensuração de questões sanitárias pelos varejistas é realizada por meio da confiança no carimbo do Serviço de Inspeção Sanitária (SIF) do Ministério da Agricultura, Pecuária e Abastecimento (MAPA). Segundo os entrevistados, todos os cortes possuem esse carimbo, sendo, portanto, verificado de forma visual.

- Embalagem: a verificação da embalagem é realizada visualmente em todas as peças. Segundo os entrevistados, uma embalagem está em conformidade quando está lacrada e com vácuo. Essa verificação é, portanto, realizada visualmente, por um profissional vinculado ao varejo, no momento do recebimento, em todos os produtos.

- Tamanho e peso: a mensuração do tamanho e do peso é realizada tanto pelos fornecedores quanto pelos varejistas por meio da pesagem. Os produtos, que são pesados pelos fornecedores, são repesados para conferência e controle. Segundo os entrevistados, tamanho e peso são dimensões relacionadas, que devem estar padronizadas. O critério para conformidade é a padronização, não havendo, portanto, exigências mínimas em peso e tamanho.

- Temperatura: a mensuração da temperatura é realizada no momento do recebimento do produto, em todas as caixas, com exceção de um varejista, que pela sua escala realiza a verificação por amostra. Um dos varejistas realiza essa mensuração pelo uso de um termômetro, em todas as caixas. Nos outros casos, ela é realizada pelo profissional responsável pelo recebimento, tanto visualmente pelo critério de ausência de umidade, quanto pelo tato, verificando se as peças estão geladas.

- Coloração: a cor é verificada visualmente em todas as peças pelo responsável pelo recebimento. Segundo os entrevistados, a cor deve ser avermelhada e clara.

A mensuração de dimensões como textura, cheiro, marmoreio e maciez, é realizada somente após a troca pelos varejistas caracterizados como restaurantes.

- Textura: a textura do produto é verificada somente após a troca, e, portanto, no momento do preparo, pelo profissional responsável por esse preparo. Essa mensuração é realizada em todas as peças, sendo que diante de não conformidade esse produto é destinado a outro preparo. Embora observa-se que há uma perda de valor do produto pelo preparo de outro produto com menor valor agregado, observou-se que não há perda na qualidade, pois, o tratamento do produto, mesmo em outro preparo, possibilita que a qualidade seja mantida. De acordo com os entrevistados o critério para avaliação da textura é não pode estar "melado".

- Cheiro: o cheiro é verificado pelo olfato, sendo que não pode estar com "cheiro forte”. É mensurado em todas as peças no momento do preparo, portanto, após o recebimento do produto. Nos casos em que não está de acordo, é destinado a outros preparos, como refogados. Da mesma forma que a textura, embora haja uma perda de valor do produto ao varejista, o tratamento do produto para outro uso faz com que a qualidade seja mantida.

- Marmoreio: segundo os entrevistados, nem todas as peças são acompanhadas de marmoreio. Contudo, os entrevistados que exigem marmoreio, especificamente em raças Wagyu, realizam a verificação de forma visual, por meio de uma comparação com uma classificação de um a oito, em todas as peças durante o preparo. Entretanto, os entrevistados afirmam que embora o marmoreio esteja associado à maciez da carne, não há perda de valor nos casos em que o marmoreio é classificado como mínimo, pois é destinado à finalidade inicial.

- Maciez: de acordo com os restaurantes entrevistados, a maciez é verificada por 
meio do tato, no momento do preparo, em todas as peças. Contudo, não há parâmetros específicos para classificação da maciez. Ademais, os restaurantes ressaltam que a maciez está diretamente relacionada à forma de preparo do produto final, sendo um atributo de difícil mensuração.

- Sabor: a verificação do sabor não é realizada antes e nem após a troca, sendo, em consenso com Azevedo (2000), um atributo de difícil mensuração. Nesses casos, a mensuração é realizada durante o consumo pelos consumidores finais. Assim como a maciez, os entrevistados afirmam que o atributo sabor está associado, além do modo de preparo, aos outros atributos valorizados.

O Quadro 3 traz as dimensões envolvidas nas transações e as formas de mensurações pelos varejistas.

Quadro 3: Dimensões envolvidas nas transações e mensuração pelos varejistas

\begin{tabular}{|c|c|c|c|}
\hline \multicolumn{5}{|c|}{ Antes da troca } \\
\hline Dimensões & $\begin{array}{c}\text { Responsável } \\
\text { pela } \\
\text { mensuração }\end{array}$ & $\begin{array}{c}\text { Forma de mensuração } \\
\text { pelo varejista }\end{array}$ & Critério \\
\hline $\begin{array}{c}\text { Raça e } \\
\text { precocidade }\end{array}$ & Certificadora & Confiança no selo & Confiança nos selos \\
\hline Sanidade & Certificadora & Confiança no selo & SIF \\
\hline Embalagem & Varejo & Visual & Lacrada e a vácuo \\
\hline Tamanho e peso & Varejo & Pesagem & Padronização \\
\hline Temperatura & Varejo & Visual/tato & Livre de umidade e gelada \\
\hline Coloração & Varejo & Visual & De cor vermelha e clara \\
\hline \multicolumn{5}{|c|}{ Após a troca } \\
\hline Textura & Varejo & Tato & Não pode estar "melando" \\
\hline Odor & Varejo & Olfato & Ausência de odor forte \\
\hline Marmoreio & Varejo & Visual & Classificação de 1 a 8 \\
\hline Maciez & Varejo & Tato & Não há parâmetros \\
\hline \multicolumn{2}{|c|}{ Não mensurado } \\
\hline Sabor & Varejo & Não mensura & Não há parâmetros \\
\hline
\end{tabular}

Fonte: Elaborado pelos autores com base nos dados primários.

Observou-se que a mensuração dos atributos envolvidos na transação é feita, em sua maioria, por meio de critérios subjetivos. Mesmo quando envolve métricas, como temperatura, sua mensuração em geral não é feita na transação, sendo apenas verificada subjetivamente. Constatou-se que os mecanismos de mensuração e verificação foram geralmente sensoriais, como a visão, o tato, a gustação e o olfato. Em consenso com Azevedo (2000) e Barzel (2005), pode-se afirmar que essa mensuração envolve aspectos subjetivos. Desta forma, os selos de certificações e marcas podem se constituir em importantes mecanismo no auxílio a mensuração dos atributos transacionados.

\subsection{DISCUSSÃO}

Foram observadas duas formas de comercialização que se diferenciam de acordo com a qualidade do produto. A carne do tipo commodity geralmente é vendida em carcaça (carne com osso), embora possa ser adquirida também em forma de cortes. Já a carne especial, ou seja, aquela com atributos de diferenciação, é vendida exclusivamente embalada e por tipo de corte, fazendo uso de selos e certificações para garantir o atendimento das especificidades do produto.

De acordo com os entrevistados, o preço pago varia em função da raça do animal e dos diferentes tipos de cortes. O preço de cortes ou carcaças oriundas de animais de 
raça Nelore é formado com base no mercado tradicional. Já o preço pago por cortes procedentes de animais das raças Angus, Bonsmara e Wagyu possuem preços superiores, que variam, segundo os entrevistados, entre $20 \%$ a $300 \%$ a mais do que o preço da carne tradicional.

Tal evidência já havia sido observada em pesquisa realizada por Brisola e Castro (2005) com consumidores em Brasília, cujo 71,8\% concordaram em pagar mais pela carne rastreada em relação aos cortes tradicionais. Um estudo semelhante realizado por Velho et al. (2009) apontou que os consumidores demandam e estão dispostos a pagar mais por alimentos que apresentem certificações que garantam a qualidade dos alimentos, o que demonstra a importância da certificação para decisão de compra. As certificações quanto à raça, qualidade e rastreabilidade são as principais referências almejadas pelos varejistas investigados, uma vez que contribuem com o processo de mensuração dos atributos transacionados, reduzindo assim assimetria de informação e possível comportamento oportunista.

Quanto à estrutura de governança, foram identificados dois tipos, mercado spot e forma híbrida. O mercado spot foi observado nas transações entre micros e pequenos varejistas e fornecedores considerados grandes. Verificou-se, nesses casos, que não há vínculo entre os agentes. Embora possa haver recorrência nas transações, ela não é suficiente para manter a sustentabilidade da transação.

A forma híbrida foi identificada nas transações nos quais o fornecedor se caracteriza como pequeno. A relação entre os agentes nesse caso é, segundo os entrevistados, mais próxima, e, portanto, há parceria envolvida. Esse tipo de estrutura de governança surge pela recorrência das transações, caracterizada pelo relacionamento de longo prazo e dependência bilateral (MÉNARD, 2004). Ainda que haja uma relação de dependência bilateral, não foi detectado o uso de contratos nas transações, ocorrendo exclusivamente pelo mecanismo de acordo verbal.

Embora as transações de carnes especiais envolvam especificidade de ativos e dimensões de difícil mensuração, não foram observadas transações organizadas pela integração vertical, como preconiza a teoria. Assim, é possível afirmar, em consenso com Barzel (2005), que em ambas as estruturas de governança identificadas o compromisso e a reputação envolvidos na transação assumem papel fundamental para o andamento das transações.

Desta forma, apesar da subjetividade na mensuração de grande parte dos atributos de qualidade, estruturas de governança mais complexas não se mostram necessárias, dada reputação e a recorrência das transações. Para alguns atributos, observou-se que os produtos transacionados são certificados por uma terceira parte de elevada reputação. Dessa forma, apoiado em Barzel (2005), constatou-se que a certificação teve papel importante na mensuração desses atributos, possibilitando, dessa forma, estruturas de governança menos complexas.

No que tange às marcas, essas não se mostraram significativas para o processo de troca. Os varejistas mensuram a qualidade da carne de forma visual e tátil, utilizando como auxílio a certificação para dimensões de difíceis mensuração. Tais achados divergem dos resultados encontrados por outros pesquisadores (WACHENHEIM; ALONSO; DUMLER, 2000; MORALES et al. 2013), que colheram evidências de que a marca é relevante para redução da incerteza diante de atributos de qualidade, e que o consumidor de carne bovina dá importância à marca.

No entanto, é pertinente enfatizar que o presente estudo foi realizado sob a perspectiva do varejista em que as transações ocorrem no mercado business to business. Conforme apontam Fernández-Barcala e González-Díaz (2006), a marca é menos importante nas transações entre empresas, do que nas transações que atendem ao consumidor final, que geralmente possuem uma quantidade menor de informações 
sobre a qualidade real do produto (FERNÁNDEZ-BARCALA; GONZÁLEZ-DÍAZ, 2006).

Estudos brasileiros (GIACOMAZZI; TALAMINI; KINDLEIN, 2017) e internacionais (SPINK et al., 2017) identificaram que consumidores podem ser influenciados por estratégias de merchandising. Todavia, identificaram que essa ação depende do perfil do consumidor (GIACOMAZZI; TALAMINI; KINDLEIN, 2017; SPINK et al., 2017). Para os autores, quanto menor o conhecimento sobre carnes, maior o espaço para que sejam influenciados pelas diferentes marcas.

\section{CONCLUSÃO}

A partir do estudo realizado, foi possível observar que as transações entre varejistas e fornecedores de carnes especiais envolvem especificidades de ativo e dimensões difíceis de serem mensuradas. no que tange as dimensões envolvidas na transação, identificou-se três tipos: aquelas mensuráveis no momento da troca, após a troca, e mensurável somente durante o consumo. o ativo transacionado é certificado no que concerne a algumas dimensões, especialmente aquelas difíceis de serem verificadas no momento da transação e relacionadas a etapas a montante da cadeia, no segmento produtor (raça e precocidade). as estruturas de governança identificadas foram de dois tipos: mercado spot e formas híbridas.

Embora as transações de carnes especiais envolvam especificidade de ativos e dimensões de difícil mensuração, as partes não adotam integração vertical, como propõe a teoria. Contatou-se nesse que as certificações atuam como papel relevante para que a troca ocorra, e portanto, para a adoção de estruturas de governança menos complexas. Essas traduzem-se em mecanismos que reduzem incertezas e contribuem com o processo de mensuração dos atributos transacionados, uma vez que a maioria dos atributos são intrínsecos, sendo de difícil mensuração.

Em contrapartida, no presente estudo, verificou-se que as marcas não exercem um papel significativo no processo de mensuração e decisão de troca. Nesse contexto, a baixa importância da marca indica um baixo desenvolvimento comercial neste produto. Para conseguir uma penetração adequada da carne bovina com marca, devem ser implementadas estratégias de comunicação que permitam ao varejista e ao cliente final associar o produto a um nível de qualidade superior.

Além da certificação, identificou-se ainda que o compromisso com a relação, e a reputação gerada pela recorrência das transações, assumem papel fundamental para o andamento das transações. Diante do exposto, foi possível concluir que selos e certificações atuam como mecanismos fundamentais para a adoção de estruturas de governança menos complexas nos casos em que as transações envolvem atributos de difícil mensuração.

Apesar disso, foi possível constatar, também, que nem todas as informações sobre os atributos de qualidade chegam até o consumidor final. Observou-se, ainda, que a comercialização de produtos provenientes de animais precoces, sem associação à raça, não envolve uma remuneração diferenciada. Uma vez que a precocidade é considerada uma diferenciação no produto, é possível concluir que nesses casos parte do valor pode estar sendo perdida. Uma vez que a continuidade desses sistemas depende do retorno aos investimentos e o interesse de todos os membros de uma cadeia, pode-se concluir que a ausência de uma remuneração diferenciada pode, no longo prazo, desestimular agentes a montante a despender esforços para tal apelo de diferenciação e comprometer a continuidade do sistema.

Do ponto de vista gerencial, o presente estudo oferece uma importante contribuição ao processo de tomada de decisão, uma vez que possibilita entender que 
as certificações exercem papel significativo no processo de mensuração da qualidade da carne bovina, envolvendo reputação e confiança como mecanismos de garantia dos direitos de propriedade. Por outro lado, abre espaço para maiores estudos com relação à marca, haja visto que ela não se apresentou relevante no presente contexto.

Assim, além de estudos que investiguem o papel da marca, sugere-se a realização de pesquisas futuras que visem analisar o comportamento do consumidor quanto a compra de carne considerada como diferenciada, e a propensão a remunerar por essas características de qualidade. Além disso, na prática, sugere-se o desenvolvimento de mecanismos que levem ao consumidor informação sobre os atributos de qualidade presentes no produto diferenciado, de forma a gerar maior aproximação desse com o segmento de produção.

O presente estudo apresenta algumas limitações, primeiro quanto ao tamanho da amostra observada, uma vez que variação representada nos resultados é limitada de acordo com o número de participantes. Este estudo envolveu apenas 10 varejistas de diferentes segmentos. Outra limitação reside no universo da pesquisa, os agentes observados transacionam no mercado business to business, consequentemente os resultados não podem ser extrapolados para relações business to consumer. Por fim, outra limitação importante se dá quanto ao ambiente institucional, sabe-se o ambiente institucional pode influenciar nos custos de transação e mensuração (WILLIAMSON, 1985; BARZEL, 2005). Desta forma, sugere-se que estudos futuros investiguem a influência das certificações e marcas nos custos de mensuração em ambientes institucionais significativamente distintos, como por exemplo países desenvolvidos e países emergentes.

\section{REFERÊNCIAS}

ABIEC - ASSOCIAÇÃO BRASILEIRA DAS INDUSTRIA EXPORTADORAS DE CARNE. Beef report: perfil da pecuária no Brasil. Relatório Anual 2019. São Paulo: Brazilian Beef, 2019. 49 p.

ASSOCIAÇÃO BRASILEIRA DE NORMAS TÉCNICAS. O que é certificação e como obtê-la? Disponível em: http://www.abnt.org.br/certificacao/o-que-e. Acesso em: 09 mar. 2019.

AZEVEDO, Paulo Furquim. Nova Economia Institucional: referencial geral e aplicações para a agricultura. Agricultura em São Paulo, v. 47, tomo 01, 2000. Disponível em: http://www.iea.sp.gov.br/out/publicacoes/asp-1-0o.htm. Acesso em 14 jun. 2016.

BÁNKUTI, Sandra Mara Schiavi. Differentiated agrifood systems (DAS): organizational arrangements for small and mid-sized farmers. In: $2^{\circ}$ SIMPÓSIO INTERNACIONAL EM AGRONEGÓCIO E DESENVOLVIMENTO, 2, 2016. Anais... Tupã: $2^{\circ}$ SIAD, UNESP, 2016.

BARCELLOS, Júlio Otávio Jardim et al. Consumer perception of Brazilian traced beef. Revista Brasileira de Zootecnia, v. 41, n. 3, p.771-774, mar. 2012.

BARDIN, Laurence. Análise de conteúdo. Lisboa: Edições 70, 1979. 
BARZEL, Yoram. Economic analysis of propriety rights. Cambridge University Press, 1997.

BARZEL, Yoram. Organizational forms and measurement costs. Journal of Institutional and Theoretical Economics, 161, p. 357-373, 2005.

BUAINAIN, Antônio Márcio; BATALHA, Mário Otávio. Cadeia produtiva da carne bovina. Brasília: IICA: MAPA/SPA, 2007.

BRISOLA, Marlon Vinícius; CASTRO, Antônio Maria Gomes de. Preferências do consumidor de carne bovina do distrito federal pelo ponto de compra e pelo produto adquirido. Caderno de Pesquisas em Administração, v.12, p. 81-99, 2005.

CALEMAN, Silvia Morales de Queiroz et al. Mecanismos de governança em sistemas agroalimentares: um enfoque nos custos de mensuração. Revista de Economia e Agronegócio, v. 4, n. 2, p. 219-240, 2006.

CALEMAN, Silvia Morales de Queiroz; SPROESSER, Renato Luiz; ZYLBERSZTAJN, Decio. Custos de mensuração e governança no agronegócio: um estudo de casos múltiplos no sistema agroindustrial da carne bovina. Organizações Rurais \& Agroindustriais, Lavras, v. 3, n. 10, p. 359-375, jul., 2008.

CEPEA - CENTRO DE ESTUDOS AVANÇADOS EM ECONOMIA APLICADA. PIB do Agronegócio. Disponível em: http://www.cepea.esalq.usp.br/pib/. Acesso em: 13 ago. 2018.

DEATON, B. James. A theoretical framework for examining the role of third-party certifiers. Food Control, V. 15, p. 615-619, 2004.

EMATER. Projeto bovinocultura de corte - resumo executivo. Disponível em: http://www.emater.pr.gov.br/modules/conteudo/conteudo.php? conteudo=63. Acesso em: 23 ago. 2019.

FERNÁNDEZ-BARCALA, Marta.; GONZÁLEZ-DÍAZ, Manuel. Brand equity in the European fruit and vegetable sector: A transaction cost approach. International Journal of Research in Marketing, v. 23, n. 1, p.31-44, mar. 2006.

GIACOMAZZI, Carla Mecca; TALAMINI, Edson; KINDLEIN, Liris. Relevance of brands and beef quality differentials for the consumer at the time of purchase.

Revista Brasileira de Zootecnia, v. 46, n. 4, p.354-365, abr. 2017.

KEHAGIA, Olga; LINARDAKIS, Michalis; CHRYSSOCHOIDIS, George. Beef traceability: are Greek consumers willing to pay? Euromed Journal of Business, v. 2 , n. 2 , p.173-190, 12 out. 2007.

KOTLER, Philip. Marketing insights from A to Z: 80 concerns every manager needs to know. New Jersey: John Wiley \& Sons, 2003.

MACEDO, Luís Otávio Bau.; MORAES, Márcia Azanha Ferraz Dias. Perfil de governança e a coordenação de alianças estratégicas da carne bovina brasileira.

Informações Econômicas, v.39, n.3, 2009. 
MAYSONNAVE, Greicy Sofia. et al. Percepção de qualidade da carne bovina com marca no sul do Brasil. Archivos de Zootecnia, v. 63, n. 244, p.633-644, dez. 2014.

MÉNARD, Claude. The economics of hybrid organizations. Journal of Institutional and Theoretical Economics Jite, v. 160, n. 3, p. 345-376, 1 set. 2004.

MERRIAM, Sharan B. Qualitative research and case study applications in education. United States of America: PB Printing, 1998.

MORALES, Emilio L. et al. Variables affecting the propensity to buy branded beef among groups of Australian beef buyers. Meat Science, v. 94, p. 239-246, 2013.

SANTOS, Leandro et al. Políticas públicas para o comércio de produtos orgânicos no Brasil. Revista de Ciências Agrárias, v. 40, n. 2, p.447-459, jun. 2017.

SPINK, John et al. Food fraud prevention shifts the food risk focus to vulnerability. Trends n Food Science \& Technology, v. 62, p.215-220, abr. 2017.

TRIENEKENS, Jacques H. Agricultural value chains in developing countries: a framework for analysis. International Food And Agribusiness Management Review, v. 14, n. 2, 2011.

TRIVIÑOS, Augusto Nibaldo Silva. Introdução à pesquisa em ciências sociais: a pesquisa qualitativa e, educação. São Paulo: Atlas, 1987.

UNITED STATES DEPARTMENT OF AGRICULTURE. Foreign Agricultural Services. Disponível em: http://apps.fas.usda.gov/psdonline/psdQuery.aspx. Acesso em: 28 fev. 2019.

VELHO, João Pedro et al. Disposição dos consumidores porto-alegrenses à compra de carne bovina com certificação. Revista Brasileira de Zootecnia, v. 38, n. 2, p.399-404, fev. 2009.

WACHENHEIM, Cheryl J.; ALONSO, Carlos; DUMLER, Michael. Marketing a branded fresh beef product. Journal of Food Products Marketing, v. 6, n. 1, p.53-79, jan. 2000.

WU, Linhai et al. Chinese consumers' preferences and willingness to pay for traceable food quality and safety attributes: the case of pork. China Economic Review, v. 35, p.121-136, set. 2015 .

ZYLBERSZTAJN, Decio. Measurement costs and governance: bridging perspectives of transaction cost economics. International Society for the New Institutional Economics, Barcelona, Espanha, 2005. 
Submetido em 16/o6/2019

Aprovado em 01/3/2020

\section{Sobre o(s) Autor(es):}

\section{Lechan Colares-Santos}

Possui graduação (2007) em Administração e mestrado (2012) em Administração pela Universidade Federal de Mato Grosso do Sul. Atualmente é Doutorando em Administração pela Universidade Estadual de Maringá (UEM) e professor mestre da Universidade do Oeste Paulista (UNOESTE). Tem experiência na área de Administração, com ênfase em Agronegócios, atuando principalmente nos seguintes temas: avaliação de desempenho, produção e logística. Email: lechan@unoeste.br

\section{Amanda Ferreira Guimarães}

Graduação em Administração pela Universidade Estadual de Maringá, Paraná, Brasil. Mestre em Administração pelo Programa de Pós-Graduação em Administração da Universidade Estadual de Maringá, Paraná, Brasil, com estágio acadêmico internacional na École I'Ingénieurs de Purpan, Toulouse, França. Doutoranda em Administração pela Universidade Estadual de Maringá na linha de Marketing e Cadeias Produtivas do Programa de Pós-Graduação em Administração da Universidade Estadual de Maringá, Paraná, Brasil. Doutorado Sanduíche realizado na École d'Ingénieurs de Purpan, Toulouse, França. Atua no projeto de extensão para desenvolvimento e valorização de produtores de cafés especiais no estado do Paraná, Brasil. Pesquisas na área de coordenação de cadeias produtivas de alto valor agregado, value chain, global value chain, com foco nas cadeias de carne bovina e cafés especiais. Email: amandafguimaraes@live.com

\section{Sandra Mara de Alencar Schiavi}

Economista pela UNESP (1998) e doutora em Engenharia de Produção pela UFSCar (2007), com estagio de doutorado (sanduiche) no ENITIAA / Université de Nantes (França) e Pós Doutorado na Kansas State University - Department of Agricultural Economics (2016). Professora do Departamento de Administração da Universidade Estadual de Maringá (UEM) e docente do Programa de Pós-graduação em Administração (PPA / UEM) e do Programa de Pós-Graduação em Ciências Econômicas (PCE/ UEM). Líder do Grupo de Estudos em Estruturas Coordenadas (GECOR), tem experiência nas áreas de Economia e Administração, com ênfase em Organização Industrial e Nova Economia Institucional. Suas pesquisas envolvem parcerias internacionais para o estudo da coordenação e competitividade de sistemas agroalimentares, Sistemas Agroalimentares Diferenciados e Values-Based Supply Chains, estruturas de governança, relações verticais e horizontais em cadeias produtivas, agricultura familiar e pequena produção. Email: smsbankuti@uem.br

\section{Iolanda Ivantes}

Graduada em Administração pela Universidade Estadual de Maringá.

Email: iolanda.ivantes@hotmail.com

\section{José Paulo de Souza}

Possui graduação em Administração pela Universidade Estadual de Maringá (1987), mestrado em Engenharia de Produção pela Universidade Federal de Santa Catarina (1999), doutorado em Engenharia de Produção pela Universidade Federal de Santa Catarina (2002) e pós-doutorado em Administração, pela Universidade de São Paulo (2008). Atualmente é professor associado no Departamento de Administração da Universidade Estadual de Maringá. Tem experiência na área de Administração, com ênfase em sistemas produtivos atuando, principalmente, nos seguintes temas: gestão de operações; competitividade sistêmica; estratégias, estruturas de governança e competitividade em sistemas agroindustriais. Email: jpsouza@uem.br 